\title{
Digesting the alphabet soup of LCA
}

\author{
Jeroen B. Guinée ${ }^{1}$ (D) · Stefano Cucurachi ${ }^{1}$ • Patrik J.G. Henriksson ${ }^{2} \cdot$ Reinout Heijungs $^{1,3}$
}

Received: 13 March 2018 / Accepted: 24 April 2018 / Published online: 23 May 2018

(C) The Author(s) 2018

Keywords Attributional LCA $\cdot$ Consequential LCA $\cdot$ Explorative LCA $\cdot$ Modes of LCA $\cdot$ Modelling

\section{Introduction}

One of the most pertinent and enduring debates within the lifecycle assessment (LCA) community is on consequential (CLCA) and attributional LCA (ALCA), see for example, Weidema et al. (1999), Guinée et al.(2002), Ekvall and Andræ (2006), Schmidt (2010), Zamagni et al. (2012), Rehl et al. (2012), Anex and Lifset (2014), Brandão et al. (2014), Suh and Yang (2014), Dale and Kim (2014), Hertwich (2014), Plevin et al. (2014a), Plevin et al. (2014b), Ekvall et al. (2016), and Weidema et al. (2018). Amongst other things, the debate focuses on similarities and differences between these two modes and on which mode is more appropriate for which case or question. Some authors claimed superiority of one of these modes over the other (Plevin et al. 2014a; Weidema et al. 2018). Here, we refrain from further dwelling on this discussion, but rather discuss the more recent emergence of other modes of LCA. These new modes have been developed by independent scholars, outside the ISO standards (International Organization for Standardisation 2006) and

Responsible editor: Mary Ann Curran

Jeroen B. Guinée

guinee@cml.leidenuniv.nl

1 Institute of Environmental Sciences (CML), Department of Industrial Ecology, Leiden University, Einsteinweg 2, 2333

CC Leiden, The Netherlands

2 Stockholm Resilience Centre, Stockholm University, 10691 Stockholm, Sweden

3 Department of Econometrics and Operations Research, Vrije Universiteit Amsterdam, De Boelelaan 1105, 1081 HV Amsterdam, The Netherlands outside national and continental guidelines (e.g., European Commission-Joint Research Centre-Institute for Environment and Sustainability 2010). They all focus on estimating life-cycle impacts of future systems and we argue that they are all varieties of analysis fitting under the umbrella of "explorative" LCA. To substantiate this, we first look into the definitions of ALCA, CLCA, and some of the newer modes of LCA. We then briefly discuss similarities and differences between these different LCA modes, and conclude that rather than discussing different modes, the LCA community should focus on discussing their underlying real differences.

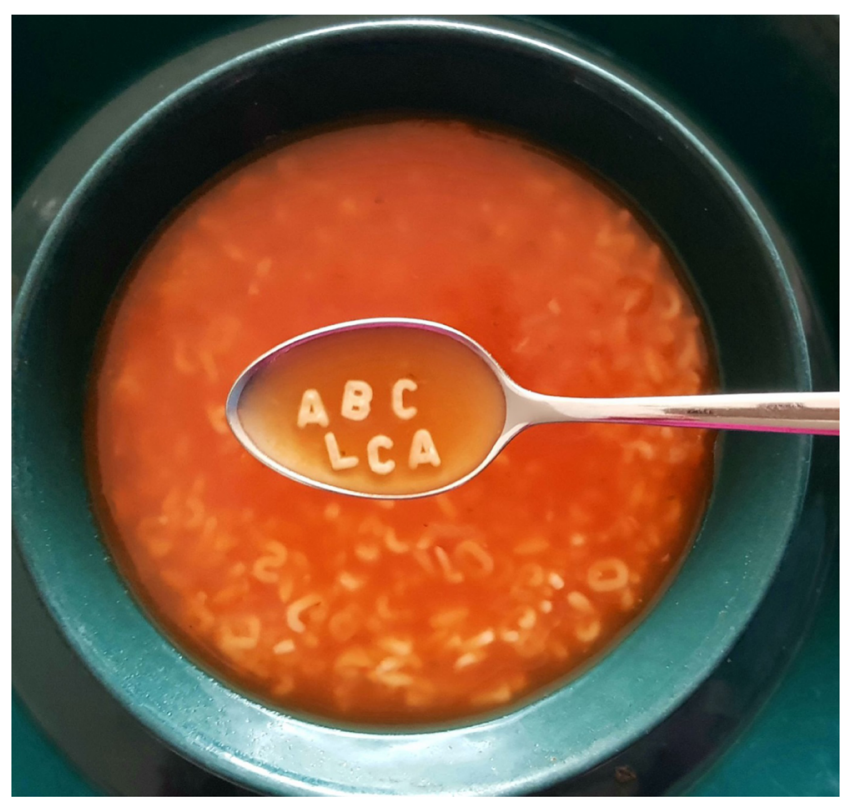




\section{Panoply of definitions}

A widely used set of definitions for ALCA and CLCA was provided in the UNEP report on "Global Guidance Principles for Life Cycle Assessment Databases” (UNEP 2011):

- Attributional LCA (ALCA): to provide information on what portion of global burdens can be associated with a specific product life cycle.

- Consequential LCA (CLCA): to provide information on the environmental burdens that occur, directly or indirectly, as a consequence of a decision (usually represented by changes in demand for a product).

In the recent LCA literature, we can find many more modes of LCA. Below, we list these other modes of LCA and provide a brief definition:

- Backcasting LCA (BLCA): exploring ways-in a lifecycle perspective - to meet normatively defined sustainability levels (planetary boundaries) through adapted affluence (as consumption levels), population growth, and/ or technologies (Heijungs et al. 2014);

- Decision LCA (DLCA): based on CLCA but using the actual or anticipated financial and contractual relations between economic actors (business-to-business relations) as the main basis of information (Frischknecht 1998; Frischknecht and Stucki 2010);

- Integrated LCA (ILCA): LCA integrated with other modeling approaches such as input-output analysis, energy-scenario modeling, and, for example, material flow analysis (Hertwich et al. 2014); method for assessing the environmental and resource implications of scenarios for large-scale adoption of climate change mitigation measures (Gibon et al. 2015);

- Anticipatory LCA (NLCA): a forward-looking, nonpredictive tool that increases model uncertainty through inclusion of prospective modeling tools, decision theory, and multiple social perspectives (Wender et al. 2014);

- Prospective LCA (PLCA): estimating future life-cycle environmental impacts using scenarios (Spielmann et al. 2005; Walser et al. 2011);

- Scenario-based LCA (SLCA): LCA based on scenarios separating three modeling processes, life-cycle modeling, scenario modeling, and valuation modeling (Fukushima and Hirao 2002).

Perhaps, there are a few more varieties that we missed. But the conclusion is clear: an alphabet soup of LCA modes has emerged. The big question is of course: what is their relation?

\section{Similarities and differences}

ALCA is the only mode focusing on modeling a situation as it is, either in the past, present, or future, but without any changes. The other modes, from BLCA up to SLCA, have a lot in common. They all aim at estimating the effects of changed situations, where the change and/or the background state are based on a scenario.
Table 1 Examples of questions addressed by different modes of LCA

\begin{tabular}{|c|c|c|}
\hline & Question & Reference \\
\hline ALCA & $\begin{array}{l}\text { What is the life-cycle impact of } 1 \mathrm{kWh} \text { of electricity at } \\
\text { grid in France in } 2006 ?\end{array}$ & (Frischknecht and Stucki 2010) \\
\hline BLCA & $\begin{array}{l}\text { What is the maximum attainable affluence for the EU } 27 \\
\text { in } 2020 \text { and } 2050 \text { to meet related EU GHG target? }\end{array}$ & (Heijungs et al. 2014) \\
\hline \multirow[t]{2}{*}{ CLCA } & $\begin{array}{l}\text { What are the consequences of an increased demand } \\
\text { of wheat in Denmark? }\end{array}$ & $\begin{array}{l}\text { (Schmidt 2010) } \\
\text { (Frischknecht and Stucki 2010) }\end{array}$ \\
\hline & $\begin{array}{l}\text { Which effect does the decision to purchase an } \\
\text { additional kWh of electricity have on the electricity } \\
\text { market and/or on the environmental impacts? }\end{array}$ & \\
\hline DLCA & $\begin{array}{l}\text { Which effect does the decision to purchase an } \\
\text { additional kWh of electricity have on the electricity } \\
\text { market and/or on the environmental impacts? }\end{array}$ & (Frischknecht and Stucki 2010) \\
\hline ILCA & $\begin{array}{l}\text { What are the system-wide life-cycle impacts of a } \\
\text { specific energy transition? }\end{array}$ & (Hertwich et al. 2014) \\
\hline NLCA & $\begin{array}{l}\text { What are the future environmental burdens associated } \\
\text { with an emerging technology for both reasonable } \\
\text { and extreme-case scenarios? }\end{array}$ & (Wender et al. 2014) \\
\hline PLCA & $\begin{array}{l}\text { What are the environmental benefits and impacts } \\
\text { of nanosilver T-shirts compared with conventional } \\
\text { T-shirts and T-shirts treated with triclosan? }\end{array}$ & (Walser et al. 2011) \\
\hline SLCA & $\begin{array}{l}\text { What is the best scenario for improving the life-cycle } \\
\text { environmental performance of a car? }\end{array}$ & (Fukushima and Hirao 2002) \\
\hline
\end{tabular}




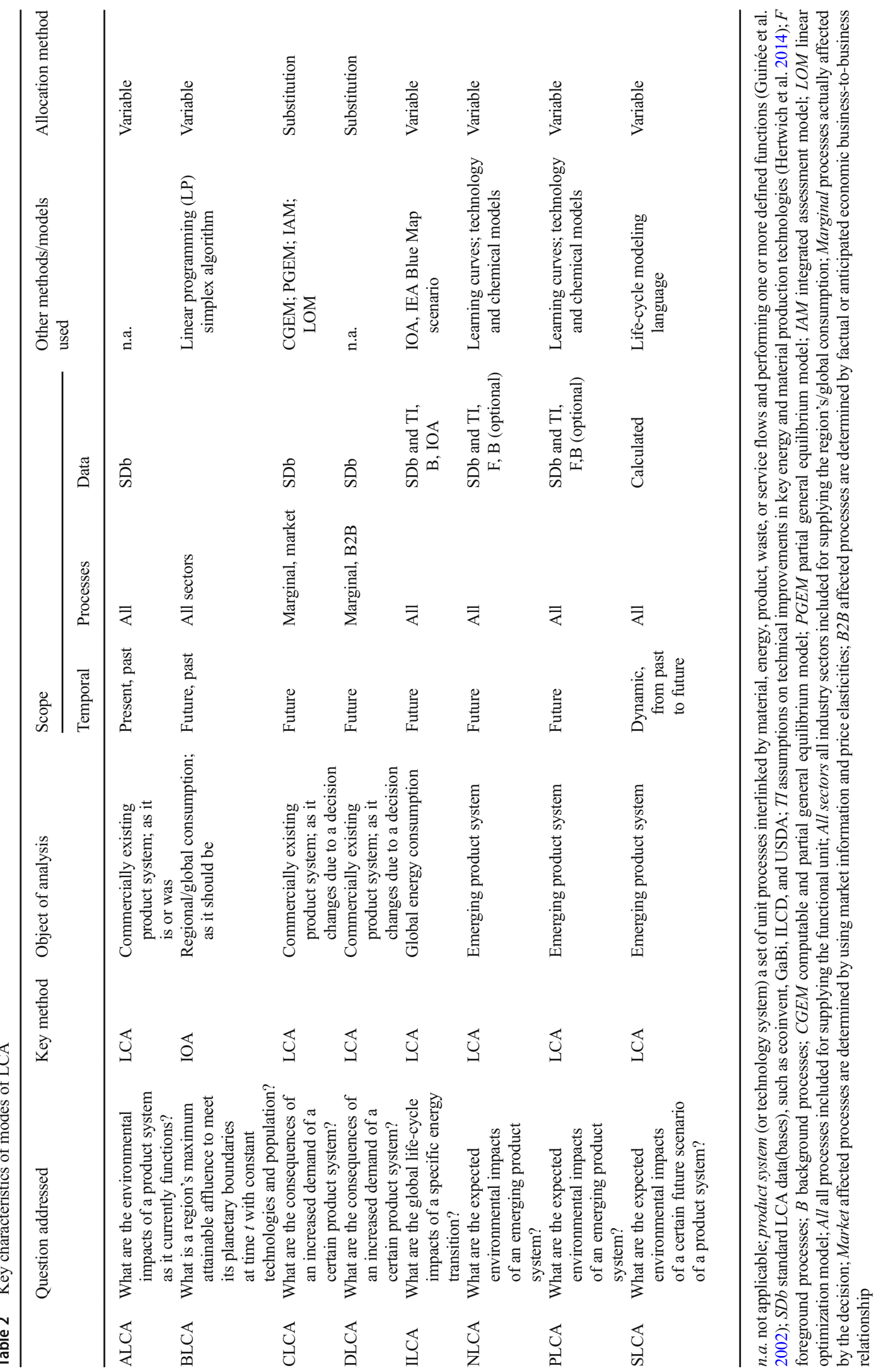


There are of course also differences between these modes regarding questions addressed (see Table 1 for some selected examples from literature), objects of analysis, processes involved, object of analysis, temporal scope, processes covered, data scope, additional methods and models adopted, and allocation methods used; see Table 2 for a summary of similarities and differences.

Table 2 shows that one main divide between modes concerns the object of analysis. Some modes mainly focus on commercially existing product systems (ALCA, CLCA, DLCA), while other modes focus on emerging, novel, and not yet marketed product systems (NLCA, PLCA, SLCA). Next, Table 2 shows that all modes except ALCA aim to assess the environmental life-cycle performance of a future system on the short, mid, or long term. CLCA then becomes just one mode out of at least six other modes to model life-cycle impacts of possible consequences of changes to existing product systems, or of introducing novel technology or product systems. Depending on the exact question posed, one of these six may be preferred, but we might also want to apply all of them and see how robust LCA results are for different assumptions that are difficult to verify or falsify (Yang and Heijungs 2018).

Another fundamental difference concerns the data requirements of the different modes: standard databases without any changes or standard databases with changes based on assumed technological improvements, supplemented by new datasets for foreground processes. As process data are one of the main drivers of final LCA results, differences at this level may have a huge effect on results.

Finally, Table 2 shows that by focusing the discussion on differences between modes, we may overlook the fact that there are also some fundamental modeling differences within one mode. This was recently exemplified for CLCA and argued to be potentially more important than differences between modes (Yang and Heijungs 2018). In addition, Table 2 shows comparable differences within NLCA and PLCA (see column "other methods/models used").

\section{Conclusions}

Over the past decade, an alphabet soup of modes of LCAs has emerged. This soup of LCA modes can be split into two main groups: ALCA is the only mode focusing on modeling a situation as it is, either in the past, present, or future, but without any changes. We suggest classifying the group of BLCAZLCA as life-cycle modeling of the unknown by exploring scenarios of potential futures, or shortly "explorative LCA." Let us call them XLCA, where $X \in\{B, C, \ldots, Z\}$, and moreover $X$ codes for eXplorative.

Each mode of LCA has its merits and demerits and we have shown that they share many similarities despite also some differences. In addition, we have shown that the methods and models used in combination with the key method (i.e., mostly LCA) may widely vary. Therefore, based on an analysis of similarities and differences between the different XLCA modes, we conclude that rather than discussing different modes, the LCA community should focus on discussing the underlying differences including the object of analysis, other methods/models used in combination with the key method, data, and scenarios adopted. Our starting position in this debate is that instead of distinguishing BLCA-ZLCA as different modes of XLCA, we actually have a multi-model multiparadigm approach within the group of XLCA (Yang and Heijungs 2018). Different questions posed will need different models and approaches and probably not just one model and one approach but rather a suite of applicable models and approaches. Selecting single models and approaches for specific questions may be a bridge too far. All models rely on strong assumption and constraints, and as LCA outcomes are largely unverifiable (Guineé et al. 2017; Yang and Heijungs 2018), claiming certain LCA modes or models to be superior cannot be supported by evidence, and this battle between schools is thus a dead-end in our view.

We strongly recommend that explorative LCA studies from here on explicitly formulate their research questions and object of analysis and justify other models, data, and scenarios selected on the basis of these questions and objects. We expect that the latter will help advance the debate on how different approaches, modes, and models may best support certain questions and decisions, which is a research topic on which little progress has been achieved so far.

We would like to conclude by paraphrasing Suh and Yang (2014): "Dividing the LCA world into CLCAs and ALCAs overlooks the studies" not fitting this divide and "hampers a constructive dialog about the creative use of modelling frameworks."

Open Access This article is distributed under the terms of the Creative Commons Attribution 4.0 International License (http:// creativecommons.org/licenses/by/4.0/), which permits unrestricted use, distribution, and reproduction in any medium, provided you give appropriate credit to the original author(s) and the source, provide a link to the Creative Commons license, and indicate if changes were made.

\section{References}

Anex R, Lifset R (2014) Life cycle assessment. J Ind Ecol 18:321-323

Brandão M, Clift R, Cowie A, Greenhalgh S (2014) The use of life cycle assessment in the support of robust (climate) policy making: comment on 'using attributional life cycle assessment to estimate climate-change mitigation'. J Ind Ecol 18:461-463

Dale BE, Kim S (2014) Can the predictions of consequential life cycle assessment be tested in the real world? comment on 'using 
attributional life cycle assessment to estimate climate-change mitigation. J Ind Ecol 18:466-467

Ekvall T, Andræ ASG (2006) Attributional and consequential environmental assessment of the shift to lead-free solders. Int J Life Cycle Assess 11:344-353

Ekvall T, Azapagic A, Finnveden G, Rydberg T, Weidema BP, Zamagni A (2016) Attributional and consequential LCA in the ILCD handbook. Int J Life Cycle Assess 21:293-296

European Commission-Joint Research Centre-Institute for Environment and Sustainability (2010) International Reference Life Cycle Data System (ILCD) handbook - general guide for life cycle assessment — detailed guidance, First edit. EUR 24708 EN. Luxem bourg. Publications Office of the European Union

Frischknecht R (1998) Life cycle inventory analysis for decision-making. Scope-dependent inventory system models and context-specific joint product allocation

Frischknecht R, Stucki M (2010) Scope-dependent modelling of electricity supply in life cycle assessments. Int J Life Cycle Assess 15:806-816

Fukushima Y, Hirao M (2002) LCA methodology a structured framework and language for scenario-based life cycle assessment. Int J Life Cycle Assess 7:317-329

Gibon T, Wood R, Arvesen A, Bergesen JD, Suh S, Hertwich EG (2015) A methodology for integrated, multiregional life cycle assessment scenarios under large-scale technological change. Environ Sci Technol 49:11218-11226

Guinée JB, Gorrée M, Heijungs R et al (2002) Handbook on life cycle assessment - operational guide to the ISO standards

Guineé JB, Heijungs R, Vijver MG, Peijnenburg WJGM (2017) Setting the stage for debating the roles of risk assessment and life-cycle assessment of engineered nanomaterials. Nat Nanotechnol 12:727-733

Heijungs R, De Koning A, Guinée JB (2014) Maximizing affluence within the planetary boundaries. Int J Life Cycle Assess 19: $1331-1335$

Hertwich E (2014) Understanding the climate mitigation benefits of product systems: comment on 'using attributional life cycle assessment to estimate climate-change mitigation. J Ind Ecol 18:464-465

Hertwich EG, Gibon T, Bouman EA et al (2014) Integrated life-cycle assessment of electricity-supply scenarios confirms global environmental benefit of low-carbon technologies. Proc Natl Acad Sci U S A 112:6277-6282

International Organization for Standardisation (2006) ISO 14044, Environmental Management-Life Cycle AssessmentRequirements and guidelines. https://doi.org/10.1007/s11367-0110297-3, 16, 652, 668

Plevin RJ, Delucchi MA, Creutzig F (2014a) Using attributional life cycle assessment to estimate climate-change mitigation benefits misleads policy makers. J Ind Ecol 18:73-83

Plevin RJ, Delucchi MA, Creutzig F (2014b) Response to 'on the uncanny capabilities of consequential LCA' by Sangwon Suh and Yi Yang (Int J Life Cycle Assess. https://doi.org/10.1007/s11367-014-07399). Int J Life Cycle Assess 19:1559-1560

Rehl T, Lansche J, Müller J (2012) Life cycle assessment of energy generation from biogas - attributional vs. consequential approach. Renew Sust Energ Rev 16:3766-3775

Schmidt JH (2010) Comparative life cycle assessment of rapeseed oil and palm oil. Int J Life Cycle Assess 15:183-197

Spielmann M, Scholz RW, Tietje O, De Haan P (2005) Scenario modelling in prospective LCA of transport systems application of formative scenario analysis. Int J Life Cycle Assess 10:325-335

Suh S, Yang Y (2014) On the uncanny capabilities of consequential LCA. Int J Life Cycle Assess 19:1179-1184

UNEP (2011) Global guidance principles for life cycle assessment databases

Walser T, Demou E, Lang DJ, Hellweg S (2011) Prospective environmental life cycle assessment of nanosilver T-shirts. Environ Sci Technol 45:4570-4578

Weidema B, Frees N, Nielsen A-M (1999) Marginal production technologies for life cycle inventories. Int J Life Cycle Assess 4:48-56

Weidema BP, Pizzol M, Schmidt J, Thoma G (2018) Attributional or consequential life cycle assessment: a matter of social responsibility. J Clean Prod 174:305-314

Wender BA, Foley RW, Hottle TA, Sadowski J, Prado-Lopez V, Eisenberg DA, Laurin L, Seager TP (2014) Anticipatory life-cycle assessment for responsible research and innovation. J Responsible Innov 1:200-207

Yang Y, Heijungs R (2018) On the use of different models for consequential life cycle assessment. Int J Life Cycle Assess 23:751-758

Zamagni A, Guinée J, Heijungs R, Masoni P, Raggi A (2012) Lights and shadows in consequential LCA. Int J Life Cycle Assess 17:904-918 